\title{
Burden of Care of Filipino Children with Epilepsy and its Impact on Quality of Life, Anxiety, and Depressive Symptoms among Caregivers
}

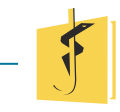

\author{
Julie Ann Kristy L. Torres, $M D^{\prime}$ \\ Rowena Arca-Cabradilla, MD' \\ Michelle G. Sy, MD' \\ Ma. Lourdes P. Corrales-Joson, $M D^{1}$ \\ Maria Antonia Moral-Valencia, $M D^{\prime}$ \\ Rosalina Q. de Sagun, MD'
}

\section{ABSTRACT \\ Background Caregiver burden and its impact on the quality of life is as important as determining the quality of life of children with epilepsy as these fac- tors influence each other as well as the outcome of these children.}

Objectives The primary objective of the study was to determine the association between caregiver burden and quality of life as well as anxiety and depressive symptoms among caregivers of Filipino children with epilepsy. Also, the study aimed to determine the prevalence rate of caregiver burden, impaired quality of life, anxiety, and depressive symptoms in an ambulatory care setting.

Methodology In this cross-sectional survey, adult caregivers accompanying their pediatric patients

$\checkmark$ Julie Ann Kristy L. Torres

julieannkristytorres@gmail.com

University of Santo Tomas Hospital, Manila, Philippines with epilepsy at a single tertiary center were recruited. Sociodemographic and clinical data were collected. The participants completed questionnaires for caregiver burden, quality of life, anxiety, and depressive symptoms.

Results Fifty-three caregivers participated with a mean age of 38 years. Most of them were females, married, unemployed, and at least college level. The mean age of their patients was 9.4 years and $71.7 \%$ of patients were on a single anti-epileptic drug. Lower educational level was less likely associated with caregiver burden. Although impaired quality of life and depressive symptoms were more likely associated with caregiver burden, this association did not reach statistical significance.

Conclusion The prevalence rate of caregiver burden, impaired quality of life, anxiety, and depressive symptoms were $24.5 \%, 22.6 \%, 28.3 \%$, and $9.4 \%$ respectively, among caregivers of Filipino children with epilepsy at a single tertiary center. 
Lower educational level was the only characteristic significantly associated with lesser odds of having caregiver burden.

Keywords caregiver burden, quality of life, anxiety, depression, children with epilepsy

\section{INTRODUCTION}

Epilepsy ranks among the top ten of the world's disease burdens and has one of the highest disability-adjusted life years (DALY) for both sexes.[1] In 2007, the prevalence of epilepsy in the Philippines was estimated at $0.9 \%$, which translates to around 800,000 Filipinos living with epilepsy.[2] Epilepsy is associated with significant physical, psychological, emotional, and social consequences for both the patients and their caregivers. $[1,3,4]$

The well-being of caregivers is now recognized as another public health concern. The level of burden experienced by caregivers and its impact on their quality of life is as important as determining the quality of life of children with epilepsy as these factors influence each other as well as the outcome of these children. Caregiving burden is a multifactorial construct that refers to the physical, emotional, and social impact of the stress of caregiving along with related feelings such as shame, grief, anger, guilt, isolation, and loss of control.[3,5] It originates from the imbalance created when care needs and the perceived internal ability to respond impairs and prevents the caregiver from the pursuit of other life objectives.[6,7] In a cohort of Asian families, the prevalence rate of mild-to-moderate caregiver burden among adult patients with epilepsy using the Zarit Burden Interview (ZBI) has been estimated to be $42.3 \%$.[8]. In a large North American cohort, the estimated prevalence of caregiver burden among pediatric and adult persons with epilepsy using the same instrument was mild-to-moderate $22 \%$, moderate-to-severe 33\%, and severe 3.6\%.[9] There has been no published literature on caregiver burden among pediatric patients with epilepsy in the Philippines as of this time.

Lower caregiver educational level, younger patient age, family history of epilepsy, residence in rural areas, older caregiver, poorer patient neuropsychological performance, higher number of antiepileptic drug (AED) use, longer disease duration and shorter periods of seizure freedom and female caregivers have all been associated with higher caregiver burden.[10-12]

Caregivers who experience a greater level of burden are found to have more physical and psychological problems including symptoms of depression and anxiety as well as increased risk of mortality. [5] Up to $50 \%$ of mothers of children with epilepsy are at risk of depression in a systematic review, in which six studies showed that $12 \%$ to $49 \%$ of mothers met clinical cut-off for depression on self-reported measures.[13] In another systematic review on parental anxiety in childhood epilepsy, $9 \%$ to $58 \%$ of participants reached clinical cut-off scores for anxiety. [14] In a prospective study of a North American cohort of caregivers, $41 \%$ and $52.8 \%$ of participants had anxiety and depressive symptoms, respectively.[9]

Emotional problems interfere with caregiving and other daily activities such that the caregiver may experience depression, anxiety, and loss of vitality. [12] Caregivers with depression have poorer interactions with their children leading to deficiencies in overall care. Maternal depressive symptoms has been negatively correlated with age and family income while a positive correlation has been found with role ambiguity, worry, low maternal education, child behavioral problems as well as the presence of comorbidities.[13,15,16]

As epilepsy impairs all aspects of health-related quality of life (HRQoL) of the affected individuals, these same factors consequently affect their caregivers. $[10,17]$ Lower patient quality of life (QoL) score has been significantly associated with higher caregiver burden.[12] If caregivers are solely responsible for medication management, the burden is higher and QoL is impaired in terms of the emotional aspect, vitality, and mental health, suggesting that demands and time required to do this task might generate more burden.[12,18] Caregivers who attended to their patients 24 hours a day are more likely to have impaired QoL as caregiving interferes with their daily activities, the physical capacity to perform daily tasks and produced feelings of fear, guilt, anxiety, and tension which could further aggravate their emotional and physical well-being.[12] The severity of epilepsy, degree of patient's disability, and degree of parents' concerns also correlate with the deterioration of quality of life.[17] On the other hand, higher educational level is associated with better QoL, possibly due to a better understanding of the patient's illness and better coping strategies 
and increased potential awareness of psychosocial support. $[3,10,19]$ In addition, younger caregiver age was also associated with better QoL as younger caregivers better understand the illness of their patients, have stronger social support or respond more positively to their situation. $[3,11,20]$ The frequency and type of seizures did not show significant association with caregiver QoL.[3,21,22] In some studies, marital status, education level, economic status, and employment status did not seem to influence caregiver burden or QoL.[12] However, it has been found that marital or family conflicts contribute to burden in patients with chronic disease.[23]

Epilepsy may also be associated with other comorbid conditions like developmental disorders, cerebral palsy, congenital anomalies, and intellectual disability. These conditions adversely influence the QoL of caregivers as they devote more time to caring for their dependent patients; neglect their own needs such as sufficient sleep, nutrition, and socialization; and become unemployed and economically burdened. They may even develop prejudice, negative attitude, and psychological distress like depression and anxiety. [24] When seizure is associated with developmental disorder, parents report more constraints compared to those with seizure alone. [24] Furthermore, these children with developmental disorders may become dependent life-long upon their caregivers, hence the caregiving process does not decrease.[25]

Caregiver burden and impairment in quality of life remains to be an unmet need in epilepsy care in the Philippines. Healthcare for epilepsy should not only be affordable to the patients but also encompass those of the caregivers. Health-related services catering to caregivers may include the development of effective educational materials, support groups, and psychotherapy services for caregivers who are in need.

The primary objective of this study conducted among caregivers of Filipino children with epilepsy was to determine the association between caregiver burden with the following factors: (1) quality of life (QoL) of the caregiver, (2) anxiety, and (3) depressive symptoms of the caregiver. The level of caregiver burden associated with these factors was compared among those caregivers of children with epilepsy with or without other comorbid disorders. The second objective of the study was to determine the caregiver- and patient-related characteristics that were associated with caregiver burden. The third objective of the study was to determine the prevalence of the following factors among caregivers of Filipino children with epilepsy in an ambulatory care setting of a single tertiary center: (1) caregiver burden, (2) impaired quality of life, (3) anxiety symptoms, and (4) depressive symptoms.

\section{METHODOLOGY}

This cross-sectional survey was conducted in ambulatory care clinics of a single tertiary care center. Adult caregivers aged 19 years old and above who accompanied their pediatric patients with epilepsy were consecutively recruited. Written informed consent was secured from each participant. Approval from the Institutional Review Board was secured prior to the conduct of the study.

Descriptive statistics were used to summarize the characteristics of the caregivers and their patients. The prevalence of caregiver burden (severe caregiver strain), quality of life, anxiety, and depressive symptoms was determined using the proportion calculation. Data from the characteristics of caregivers of children with epilepsy and those with epilepsy and comorbid disorder were compared using independent student's T-test (2-tailed) or chi $^{2}$ analysis. Associations between caregiver burden (severe caregiver strain) and impaired QoL and presence of anxiety and depressive symptoms were determined using odds ratio with $95 \%$ confidence interval. Univariate analysis between caregiver strain (as a main outcome of interest) and the caregiver- and patient-related characteristics were determined using the $\mathrm{Chi}^{2}$ analysis to yield crude odds ratios with a $95 \%$ confidence interval. The null hypothesis was rejected at $0.05 \alpha$-level of significance. Epilnfo software (version 7) and Microsoft Excel were used for data analysis.

There were three self-reported measures used in this study. The Modified Caregiver Strain Index Pilipino (MCSI-P) is an adapted and validated self-administered scale that detects the presence of caregiver strain, especially those who care for terminally or chronically ill patients.[26,27] The scale has high internal consistency and good reliability. The scoring grid is as follows: $\leq 23$ - no strain; 24 to 28 predisposition to strain; and $\geq 29$ - severe caregiver strain. Higher total scores represent higher levels of caregiver strain. The World Health Organization-5 (WHO-5) Index of Well Being Pilipino is a translated 
5-item generic global rating self-administered scale measuring subjective well-being.[28] As an outcome measure, its clinical validity is very high as it can be used regardless of the underlying illness and across varied settings.[29] The scale contains only positively phrased items relating to mood, vitality, and general interests as the WHO considers positive well-being to be synonymous with mental health. A percentage score of above 50 indicates a better state of well-being or quality of life. The Hospital Anxiety and Depression Scale (HADS) Pilipino is a 14-item self-administered scale developed by Zigmond and Snaith in 1983 to identify possible and probable (caseness) anxiety and depression among patients in non-psychiatric hospital clinics.[30,31] According to the study by de Guzman [30] using the Pilipino version of the scale, the optimal cut-off score recommended for Filipinos is 11 , with a sensitivity of $75 \%$ and a specificity of $70 \%$, and a positive predictive value (PPV) of $75 \%$ based on Receiver Operating Characteristics (ROC). The severity of anxiety and depression is graded as follows: 0-7 (normal), 8-10 (mild), 11-14 (moderate) and 15-21 (severe). Permission to use the MCSI-P and HADS-P scales was granted by the corresponding authors.

\section{RESULTS}

\section{Caregiver and patient characteristics}

Although the pre-determined sample size of 90 participants was not reached, a total of 53 caregivers were included in the study with a mean age of 38 years. Caregivers were mostly females (94.3\%) and mothers $(79.2 \%)$, married $(36.7 \%)$, college or postgraduate degree holders $(56.6 \%)$, unemployed or retired $(60.4 \%)$, living with relatives $(57.7 \%)$, and not caring for another person with a disability $(88.7 \%)$. The mean number of children in the household was 2.7. Almost half of the caregivers reported that the estimated household annual income in 2017 was $>100,000$ pesos $(54.7 \%)$. The average monthly expenditure for treatment of epilepsy or other underlying medical conditions was 2,786 pesos. There were no significant statistical differences in the variables between the two groups.

The demographic and clinical data of 53 patients were also collected in this study. There were more patients with comorbid disorders $(n=35)$ compared to those who did not $(n=18)$. The mean age of the patients was 9.4 years and $51 \%$ of the group was male. The mean duration of AED treatment was 4.1 years, with $71.7 \%$ of patients receiving monotherapy for epilepsy. Most were reported to have at least one seizure episode in the past six months $(71.7 \%)$. Intellectual disability (26), cerebral palsy (7), and asthma (2) were the most commonly reported comorbid disorders. A majority of the patients were not receiving other forms of treatment for comorbidities (38 out of 53, 71.7\%). Some mothers claimed that they could not afford to pay for other forms of therapy despite the medical advice of their physicians.

Table 1. Sociodemographic and clinical characteristics of caregivers $(n=53)$ and children with epilepsy $(n=53)$

\begin{tabular}{|c|c|c|c|c|}
\hline Characteristic of caregivers & $\begin{array}{l}\text { All participants } \\
(n=53)\end{array}$ & $\begin{array}{l}\text { Epilepsy with comorbidity } \\
\text { (n = 35) }\end{array}$ & $\begin{array}{l}\text { Epilepsy alone } \\
\text { ( } n=18 \text { ) }\end{array}$ & p-Value \\
\hline Age in years, mean $\pm S D$ & $38.0 \pm 10.2$ & $38.5 \pm 9.0$ & $37.6 \pm 12.5$ & 0.79 \\
\hline $\begin{array}{l}\text { Sex, } \mathrm{n}(\%) \\
\text { Male } \\
\text { Female }\end{array}$ & $\begin{array}{l}3(5.7 \%) \\
50(94.3 \%)\end{array}$ & $\begin{array}{l}2(5.7 \%) \\
33(94.3 \%)\end{array}$ & $\begin{array}{l}1(5.6 \%) \\
17(94.4 \%)\end{array}$ & 0.98 \\
\hline $\begin{array}{l}\text { Marital Status, n (\%) } \\
\text { Married } \\
\text { Single/widow }\end{array}$ & $\begin{array}{l}36(67.9 \%) \\
17(32.2 \%)\end{array}$ & $\begin{array}{l}26(74.3 \%) \\
9(25.7 \%)\end{array}$ & $\begin{array}{l}10(55.6 \%) \\
8(44.4 \%)\end{array}$ & 0.17 \\
\hline $\begin{array}{l}\text { Education, } \mathrm{n}(\%) \\
\text { High school level or lower } \\
\text { College or postgraduate }\end{array}$ & $\begin{array}{l}23(43.4 \%) \\
30(56.6 \%)\end{array}$ & $\begin{array}{l}16(45.7 \%) \\
19(54.3)\end{array}$ & $\begin{array}{l}7(38.9 \%) \\
11(61.1 \%)\end{array}$ & 0.63 \\
\hline $\begin{array}{l}\text { Employment Status, n (\%) } \\
\text { Employed } \\
\text { Unemployed/retired }\end{array}$ & $\begin{array}{l}21(39.6 \%) \\
32(60.4 \%)\end{array}$ & $\begin{array}{l}14(40.0 \%) \\
21(60.0 \%)\end{array}$ & $\begin{array}{l}7(38.9 \%) \\
11(61.1 \%)\end{array}$ & 0.94 \\
\hline $\begin{array}{l}\text { Relationship to the patient, n (\%) } \\
\text { Mother } \\
\text { Other relative or non-relative }\end{array}$ & $\begin{array}{l}42(79.2 \%) \\
11(20.8 \%)\end{array}$ & $\begin{array}{l}28(80.0 \%) \\
7(20.0 \%)\end{array}$ & $\begin{array}{l}14(77.8 \%) \\
4(22.2 \%)\end{array}$ & 0.85 \\
\hline
\end{tabular}




\begin{tabular}{|c|c|c|c|c|}
\hline Characteristic of caregivers & $\begin{array}{l}\text { All participants } \\
(n=53)\end{array}$ & $\begin{array}{l}\text { Epilepsy with comorbidity } \\
(\mathrm{n}=35)\end{array}$ & $\begin{array}{l}\text { Epilepsy alone } \\
(n=18)\end{array}$ & p-Value \\
\hline Living with relatives, $\mathrm{n}(\%)$ & & & & 0.64 \\
\hline Yes & $30(57.7 \%)$ & $19(54.3 \%)$ & $11(61.1 \%)$ & \\
\hline No & $23(43.4 \%)$ & $16(45.7 \%)$ & $7(38.9 \%)$ & \\
\hline $\begin{array}{l}\text { Number of children in the household, } \\
\text { mean } \pm \text { SD }\end{array}$ & $2.7 \pm 1.5$ & $2.8 \pm 1.6$ & $2.4 \pm 1.1$ & 0.24 \\
\hline $\begin{array}{l}\text { Caring for another with a disability, } \\
\mathrm{n}(\%)\end{array}$ & & & & 0.97 \\
\hline Yes & $6(11.3 \%)$ & $4(11.4 \%)$ & $2(11.1 \%)$ & \\
\hline No & $47(88.7 \%)$ & $31(88.6 \%)$ & $16(88.9 \%)$ & \\
\hline $\begin{array}{l}\text { Estimated annual family income in } \\
2017\end{array}$ & & & & 0.93 \\
\hline$\leq 100,000, \mathrm{n}(\%)$ & $24(45.3 \%)$ & $16(45.7 \%)$ & $8(44.4 \%)$ & \\
\hline$>100,000, \mathrm{n}(\%)$ & $29(54.7 \%)$ & $19(54.3 \%)$ & $10(55.6 \%)$ & \\
\hline $\begin{array}{l}\text { Average monthly expenditure for } \\
\text { treatment } / s \text {, mean } \pm S D\end{array}$ & $2,786 \pm 2,744.4$ & $3,092 \pm 3,160.5$ & $\begin{array}{l}2,191 \pm \\
1,578.8\end{array}$ & 0.17 \\
\hline \multicolumn{5}{|l|}{$\begin{array}{l}\text { Characteristics of children } \\
\text { with epilepsy }\end{array}$} \\
\hline Age, mean $\pm S D$ & $9.4 \pm 5.6$ & $9.9 \pm 5.3$ & $8.6 \pm 6.1$ & 0.46 \\
\hline$<2$ years, $\mathrm{n}(\%)$ & $4(7.5 \%)$ & $2(5.7 \%)$ & $2(11.1 \%)$ & \\
\hline $2-6$ years, $n(\%)$ & $13(24.5 \%)$ & $8(22.9 \%)$ & $5(27.8 \%)$ & \\
\hline $7-12$ years, $n(\%)$ & $19(35.8 \%)$ & $14(40.0 \%)$ & $5(27.8 \%)$ & \\
\hline $13-18$ years, $n(\%)$ & $17(32.1 \%)$ & $11(31.4 \%)$ & $6(33.3 \%)$ & \\
\hline Sex, n (\%) & & & & 0.92 \\
\hline Male & $27(50.9 \%)$ & $17(48.6 \%)$ & $9(50.0 \%)$ & \\
\hline Female & $26(49.1 \%)$ & $18(51.4 \%)$ & $9(50.0 \%)$ & \\
\hline Duration on treatment, mean $\pm S D$ & $4.1 \pm 4.8$ & $5.3 \pm 5.3$ & $1.8 \pm 2.3$ & 0.001 * \\
\hline Number of AED, median (IQR) & $1(1-4)$ & $1(1-4)$ & $1(1-2)$ & 0.05 \\
\hline Single drug, $n(\%)$ & $38(71.7 \%)$ & $22(62.9 \%)$ & $16(88.9 \%)$ & \\
\hline 2 or more, $n(\%)$ & $15(28.3 \%)$ & $13(37.1 \%)$ & $2(11.1 \%)$ & \\
\hline $\begin{array}{l}\text { Number of seizures, } \\
\text { median (IQR) }\end{array}$ & $1(1-50)$ & $1(1-50)$ & $1(1-30)$ & 0.95 \\
\hline None, n (\%) & $15(28.3 \%)$ & $10(28.6 \%)$ & $5(27.8 \%)$ & \\
\hline$\geq 1, n(\%)$ & $38(71.7 \%)$ & $25(71.4 \%)$ & $13(72.2 \%)$ & \\
\hline \multicolumn{5}{|l|}{ Other treatment, n (\%) } \\
\hline None & 38 (71.7\%) & 20 & 18 & \\
\hline Physical therapy & - & 9 & - & \\
\hline Speech therapy & - & 2 & - & \\
\hline Occupational therapy & - & 7 & - & \\
\hline
\end{tabular}

* - statistically significant

Table 1 shows a summary of the demographic and clinical characteristics for children with epilepsy and their caregivers - categorized according to the presence or absence of comorbid disorders. There were no significant statistical differences in the variables between the two groups except for duration of treatment ( $p$-value 0.001).

\section{Caregiver burden}

Using the MCSI-P, the prevalence rate of caregiver strain (predisposition to or severe caregiver strain) among the caregivers who participated in the study was determined to be $24.5 \%$. The majority did not report caregiver strain $(75.5 \%)$, even those among 
Table 2. Level of caregiver burden among caregivers of Filipino children with epilepsy.

\begin{tabular}{|c|c|c|c|c|}
\hline Level & $\begin{array}{l}\text { All participants } \\
(n=53)\end{array}$ & $\begin{array}{l}\text { Epilepsy alone } \\
\text { (n = 18) }\end{array}$ & $\begin{array}{l}\text { Epilepsy with } \\
\text { comorbidity } \\
\text { ( } n=35 \text { ) }\end{array}$ & p-Value \\
\hline No strain, n (\%) & $40(75.5 \%)$ & $15(83.3 \%)$ & $25(71.4 \%)$ & \\
\hline Predisposition to strain, $\mathrm{n}(\%)$ & $6(11.3 \%)$ & $1(5.6 \%)$ & $5(14.3 \%)$ & 0.57 \\
\hline Severe caregiver strain, $\mathrm{n}(\%)$ & $7(13.2 \%)$ & $2(11.1 \%)$ & $5(14.3 \%)$ & \\
\hline
\end{tabular}

caregivers whose patients had other comorbid disorders (25 out of $35,71.4 \%$ ). Between the two groups, there was no significant statistical difference between the levels of caregiver strain (Table 2).

\section{QoL}

Forty-one out of the 53 caregiver participants in the study had a good QoL (77.4\%) as determined by the WHO-5 Index of Well-Being (Table 3), even among those who had patients with comorbid disorders $(80 \%)$. In this population, the prevalence of impaired quality of life was $22.6 \%$. Between the two groups, there was no significant statistical difference in the level of QoL.
Psychological symptoms of anxiety and depression

Out of the 53 participants, only a few were determined to have anxiety and depressive symptoms using the HADS - anxiety symptoms $28.3 \%(n=15)$ and depressive symptoms $9.4 \%(n=5)$. Between the two groups, there was no significant statistical difference in the presence of anxiety or depressive symptoms. Table 4 shows a summary of the presence of psychological symptoms between the two groups.

Association between caregiver burden, QoL, and psychological symptoms

In this study, participants who had caregiver burden were more likely to have impaired QoL (OR 8.2, 95\% Cl 1.9-34.3, p-value 0.004) and depressive symptoms (OR 17.3, 95\% Cl 1.7-174.3,

Table 3. Quality of life among caregivers of Filipino children with epilepsy.

\begin{tabular}{llll}
\hline Level & $\begin{array}{l}\text { All participants } \\
(\mathbf{n}=53)\end{array}$ & $\begin{array}{l}\text { Epilepsy alone } \\
(\mathbf{n}=18)\end{array}$ & $\begin{array}{l}\text { Epilepsy with } \\
\text { comorbidity } \\
\text { (n=35) }\end{array}$ \\
\hline Not impaired $(>50 \%), \mathrm{n}(\%)$ & $41(77.4 \%)$ & $13(72.2 \%)$ & $28(80.0 \%)$ \\
Impaired $(\leq 50 \%), \mathrm{n}(\%)$ & $12(22.6 \%)$ & $5(27.8 \%)$ & $7(20.0 \%)$ \\
\hline
\end{tabular}

Table 4. Psychological symptoms among caregivers of Filipino children with epilepsy.

\begin{tabular}{|c|c|c|c|c|}
\hline Symptom & $\begin{array}{l}\text { All participants } \\
(n=53)\end{array}$ & $\begin{array}{l}\text { Epilepsy alone } \\
\text { ( } n=18 \text { ) }\end{array}$ & $\begin{array}{l}\text { Epilepsy with } \\
\text { comorbidity } \\
\text { (n=35) }\end{array}$ & p-Value \\
\hline With anxiety symptoms, n (\%) & $15(28.3 \%)$ & $7(38.9 \%)$ & $8(22.9 \%)$ & 0.22 \\
\hline With depressive symptoms, n (\%) & $5(9.4 \%)$ & $2(11.1 \%)$ & $3(8.6 \%)$ & 0.77 \\
\hline
\end{tabular}


Table 5. Association between caregiver burden and quality of life and psychological symptoms.

\begin{tabular}{llll}
\hline Variable & Odds Ratio & $95 \% \mathrm{Cl}$ & $\mathrm{p}$-value \\
\hline Impaired quality of life & 8.2 & $1.9-34.3$ & 0.004 \\
Anxiety symptoms & 3.0 & $0.8-11.0$ & 0.11 \\
Depressive symptoms & 17.3 & $1.7-174.3$ & 0.02 \\
\hline
\end{tabular}

Table 6. Association between caregiver and patient characteristics and caregiver burden.

\begin{tabular}{llll}
\hline Caregiver characteristics & Odds Ratio & $95 \% \mathrm{Cl}$ & p-value \\
\hline Age $>40$ & 0.7 & $0.2-2.5$ & 0.55 \\
Female sex & 0.6 & $0.5-7.6$ & 0.72 \\
Lower educational level & 0.2 & $0.03-0.8$ & $0.02^{*}$ \\
Married & 3.3 & $0.6-17.0$ & 0.15 \\
Unemployed & 12.0 & $1.4-101.2$ & 0.02 \\
Mother & 4.0 & $0.5-34.8$ & 0.21 \\
Living with other relatives & 0.4 & $0.1-1.4$ & 0.14 \\
$\geq 2$ children & 1.1 & $0.3-4.9$ & 0.89 \\
Caring for another disabled & 1.6 & $0.3-10.1$ & 0.60 \\
Household income $<100,000$ & 1.6 & $0.5-5.6$ & 0.48 \\
Patient characteristics & & & 0.43 \\
Age $<13$ years & 1.8 & $0.4-7.6$ & 0.26 \\
Duration of treatment $>5$ years & 2.2 & $0.6-8.2$ & 0.11 \\
Multiple AEDs & 3.0 & $0.8-11.0$ & 0.66 \\
Presence of comorbidities & 1.4 & $0.4-5.2$ & \\
\hline
\end{tabular}

* - statistically significant

$p$-value 0.02) compared to those who were not burdened (Table 5). However, there was insufficient evidence to determine whether this difference was statistically significant. Anxiety symptoms were not significantly associated with caregiver burden. Association between caregiver burden and caregiver and patient characteristics (Table 6)

Participants who had attained a lower educational level were less likely to have caregiver burden compared to those who were college or postgraduate degree holders (OR $0.2,95 \% \mathrm{Cl} 0.03-0.8$, $p$-value 0.02). Although the odds of having caregiver burden were more likely if unemployed (OR $12.0,95 \% \mathrm{Cl} 1.4-101.2, p$-value 0.02 ), there was insufficient evidence to conclude that this likelihood was statistically significant. Other caregiver characteristics were not significantly associated with caregiver burden. In terms of patient-related characteristics, there was no significant association between younger age, longer duration of treatment, polytherapy, and presence of comorbid disorders and caregiver burden. 


\section{DISCUSSION}

The well-being of caregivers is another public health concern as any other chronic illness. The level of burden experienced by caregivers and its impact on their QoL is as important as determining the QoL of children with epilepsy as these factors influence each other as well as the outcome and prognosis of these children. This study was implemented in order to ascertain whether Filipino caregivers, like their Western counterparts, also experience caregiver burden while caring for a child with epilepsy and how caregiver burden is associated with QoL as well as psychological symptoms among Filipino caregivers.

\section{Caregiver burden and QoL of caregivers}

Among the 53 caregivers who participated in this study, 13 were determined to have caregiver strain/ burden, while 13 had impaired QoL. Hence, the prevalence rate of caregiver burden and impaired QoL among caregivers of children with epilepsy at a single tertiary care center ambulatory setting is $24.5 \%$ and $22.6 \%$, respectively. Although the prevalence rates are high, it is important to note that the number of participants in this study was insufficient to conclude whether these data could be generalized to a larger population of similar caregivers in the locale. Also, the prevalence rates derived from this study are well within the range reported in published data from other countries (20\% to $40 \%)$. This is despite the fact that different types of self-reported measures were used.

The caregiver burden can largely impact the QoL of caregivers as the level of burden correlates negatively with the QoL.[3] The present study showed that although the odds of having an impaired QoL were 8.2 times higher when caregivers experience significant burden, the significance of this change is inconclusive. Perhaps the insufficient size of the study population might have affected this.

Several factors were found to be associated with caregiver burden in published literature. Older caregivers have been shown to have higher caregiver burden [10] but in this study, there was no significant association between age and caregiver burden. Higher education confers a better understanding of illness as well as coping strategies and increased awareness of psychosocial support. $[3,10,19]$ Furthermore, marital, economical, and employment status did not seem to influence caregiver burden or QoL.[12] In the present study, however, lower educational level was less likely associated with caregiver burden. Filipinos are known to be religious, family-oriented and close-knit, hence psychosocial support from relatives or religious groups may mitigate caregiver burden irrespective of the level of education attained. To prove this point further, the present study showed that living with relatives, being married, unemployment, caring for another disabled individual, having two or more children in the household, lower household income were not significantly associated with caregiver burden despite the fact that these factors may be sources of additional stressors and/or responsibilities for the caregiver. These findings may suggest that indeed Filipino family members help each other out in times of need, therefore, easing the burden of care.

Apart from these, characteristics related to patients with epilepsy may also contribute to caregiver burden. These include younger patient age, the severity of epilepsy, longer duration of disease, a higher number of AEDs, and even poorer patient neuropsychological performance (albeit arising from other comorbid conditions like intellectual disability). $[10,11,17]$ Comorbid conditions may also contribute to caregiver burden and impaired QoL as the caregiver may devote more time, energy, and financial resources to the care of the patient.[24,25,33] Nevertheless, in the present study, younger age, treatment duration $>5$ years, polytherapy and comorbidities were not significantly associated with caregiver burden. A larger sample of participants may help draw more conclusive evidence to prove this association among Filipino patients.

\section{Caregiver burden and psychological symptoms}

In this study, the prevalence rate of anxiety symptoms $(28.3 \%)$ among the caregivers was well within the range published in a systematic review. However, the prevalence rate of depression symptoms $(9.4 \%)$ was slightly lower compared to other studies.

There is an established link between caregiver stress and increased risk of anxiety and depression and there may be worsening of symptoms as the time allotted to caregiving increases.[5] In this study, participants who had a caregiver burden were 17.3 times more likely to have depressive symptoms compared to those who were not burdened, but the 
significance of this change was also inconclusive. Although there was no significant association between caregiver burden and anxiety symptoms, it was observed that more caregivers reported anxiety than depressive symptoms. Caregivers do not only deal with epilepsy itself but also other physical, emotional, and psychosocial factors, which play important roles in the life of a child. As such feelings of tension, apprehension, and notably anxiety may surface when caregivers (as parents) are faced not only with issues regarding the child's health, but also with education, social, and financial support. As a matter of fact, some of the participants in this study reported having feelings of anxiety stemming from their fears regarding the seizure episode itself as the child may be harmed during the event. The child's capacity for self-care as he grows older is also a source of anxiety for some of the caregivers.

\section{CONCLUSION}

Although the sample size was insufficient, this study was able to draw several important findings. The estimated prevalence rates of caregiver burden, impaired QoL, anxiety, and depressive symptoms were $24.5 \%, 22.6 \%, 28.3 \%$, and $9.4 \%$, respectively among caregivers of Filipino children with epilepsy at a single tertiary care center. Caregivers who experienced significant burden were more likely to have impaired QoL and depressive symptoms. However, there was insufficient evidence to conclude if these associations were statistically significant. The lower educational level of the caregiver was the only characteristic that was significantly associated with lesser odds of having caregiver burden.

\section{RECOMMENDATIONS}

Since the sample size was not reached in this study, the statistical significance of some of the findings could not be conclusively made. Hence, a larger cohort of caregivers would suffice to derive more robust clinical data and precise statistical findings. Furthermore, a qualitative study with focused-group discussion is recommended as there are several psychodynamic factors relating to patient- and caregiver-perspectives on caregiving. Screening for caregiver burden is a worthwhile endeavor during outpatient consultations as those who need intervention can be easily identified and aided. An interventional study focused on coping strategies among those with caregiver burden is also worth exploring.

\section{DISCLOSURE OF INTEREST}

The authors have no conflicting interests to disclose with regards to the conduct and publication of the study.

\section{ACKNOWLEDGMENT}

The authors wish to thank all the caregivers who willingly gave their time to participate in this study. 


\section{REFERENCES}

1. Beghi E. Addressing the burden of epilepsy: many unmet needs. Pharmacological Research. 2016 May $1 ; 107: 79-84$.

2. Annabell $\mathrm{CH}$. Epilepsy surgery in the Philippines. Neurology Asia. 2007; 12(2):43-5.

3. Gutierrez-Angel AM, Martinez-Juarez IE, Hernandez-Vanegas LE, Crail-Melendez D. Quality of life and level of burden in primary caregivers of patients with epilepsy: Effect of neuropsychiatric comorbidity. Epilepsy \& Behavior. 2018 Apr 1;81:12-7.

4. Austin JK, Caplan R. Behavioral and psychiatric comorbidities in pediatric epilepsy: toward an integrative model. Epilepsia. 2007 Sep;48(9): 1639-51.

5. Phillips AC, Gallagher S, Hunt K, Der G, Carroll D. Symptoms of depression in non-routine caregivers: the role of caregiver strain and burden. British Journal of Clinical Psychology. 2009 Nov;48(4):335-46.

6. Piran P, Khademi Z, Tayari N, Mansouri N. Caregiving burden of children with chronic diseases. Electron Physician. 2017 Sep 25;9(9):5380-7.

7. Basaran A, Karadavut KI, Uneri SO, Balbaloglu O, Atasoy $N$. The effect of having a children with cerebral palsy on quality of life, burn-out, depression and anxiety scores: A comparative study. Eur J Phys Rehabil Med. 2013;49(6):815-22.

8. Lai S-T, Tan W-Y, Wo MC-M, Lim K-S, Ahmad SB, Tan C-T. Burden in caregivers of adults with epilepsy in Asian families. Seizure. 2019 Jul;71:132-9.

9. Helmers S, Gupta S, Huang S, Berk A, Knoth R. Caregiver Burden: An Under-Recognized Aspect of Epilepsy Care. 2015.

10. Karakis I, Cole AJ, Montouris GD, San Luciano M, Meador KJ, Piperidou C. Caregiver Burden in Epilepsy: Determinants and Impact. Epilepsy Res Treat. 2014;2014:1-9.

11. Tajudeen Nuhu F, Jika Yusuf A, Akinbiyi A, Oluyinka Fawole J, Joseph Babalola O, Titilope Sulaiman Z, et al. The burden experienced by family caregivers of patients with epilepsy attending the government psychiatric hospital, Kaduna, Nigeria. Pan Afr Med J. 2010 Jun 1;5:16.

12. Westphal-Guitti AC, Alonso NB, Migliorini RCVP, da Silva TI, Azevedo AM, Caboclo LOSF, et al. Quality of life and burden in caregivers of patients with epilepsy. J Neurosci Nurs. 2007 Dec;39(6):354-60.

13. Ferro MA, Speechley KN. Depressive symptoms among mothers of children with epilepsy: a review of prevalence, associated factors, and impact on children. Epilepsia. 2009 Nov;50(1 1):2344-54.

14. Jones C, Reilly C. Parental anxiety in childhood epilepsy: A systematic review. Epilepsia. 2016;57(4):529-37.

15. Shore CP, Austin JK, Dunn DW. Maternal adaptation to a child's epilepsy. Epilepsy Behav. 2004 Aug;5(4):557-68.

16. Mu P-F, Kuo H-C, Chang K-P. Boundary ambiguity, coping patterns and depression in mothers caring for children with epilepsy in Taiwan. Int J Nurs Stud. 2005 Mar;42(3):273-82.

17. Cianchetti C, Messina P, Pupillo E, Crichiutti G, Baglietto $M G$, Veggiotti $P$, et al. The perceived burden of epilepsy: Impact on the quality of life of children and adolescents and their families. Seizure. 2015 Jan;24:93-101.

18. Bull M. Factors influencing family caregiver burden and health. West J Nurs Res. 1990 Dec;12(6):756-8.
19. Ohaeri JU, Awadalla AW, Farah AA. Quality of life in people with epilepsy and their family caregivers. An Arab experience using the short version of the World Health Organization quality of life instrument. Saudi Med J. 2009 Oct;30(10): 1328-35.

20. Saburi G. Stressors of caregivers of school-age children with epilepsy and use of community resources. J Neurosci Nurs. 2011 Jun;43(3):E1-12.

21. van Andel J, Zijlmans M, Fischer K, Leijten FSS. Quality of life of caregivers of patients with intractable epilepsy. Vol. 50, Epilepsia. United States; 2009. p. 1294-6.

22. Lee MMK, Lee TMC, Ng PKK, Hung ATF, Au AML, Wong VCN. Psychosocial Well-Being of Carers of People with Epilepsy in Hong Kong. Epilepsy Behav. 2002 Apr;3(2): 147-57.

23. Chou KR. Caregiver burden: a concept analysis. J Pediatr Nurs. 2000 Dec; 15(6):398-407.

24. Spindler UP, Hotopp LC, Bach VA, Hornemann F, Syrbe $S$, Andreas A, et al. Seizure disorders and developmental disorders: impact on life of affected families-a structured interview. Eur J Pediatr. 2017;176(8):1121-9.

25. McCann D, Bull R, Winzenberg T. The daily patterns of time use for parents of children with complex needs: a systematic review. J Child Health Care. 2012 Mar; 16(1):26-52.

26. Bautista M, Yu-Maglonzo E, Pilares-Cruz M. Modified Caregiver Strain Index. The Filipino Family Physician. 2007;45:1-7.

27. Robinson BC. Validation of a Caregiver Strain Index. J Gerontol. 1983 May;38(3):344-8.

28. Topp CW, Ostergaard SD, Sondergaard S, Bech P. The WHO-5 Well-Being Index: a systematic review of the literature. Psychother Psychosom. 2015;84(3):167-76.

29. Hall T, Krahn GL, Horner-Johnson W, Lamb G. Examining functional content in widely used Health-Related Quality of Life scales. Rehabil Psychol. 2011 May;56(2):94-9.

30. De Guzman MLRE. A validation of the Hospital Anxiety and Depression Scale (HADS) in the medically-ill. Acta Med Philipp. 2013;47(3):53-62.

31. Zigmond AS, Snaith RP. The hospital anxiety and depression scale. Acta Psychiatr Scand. 1983 Jun;67(6):361-70.

32. Bjellan I, Dahl AA, Haug TT, Neckelmann D. The validity of the Hospital Anxiety and Depression Scale: an updated literature review. J Psychosom Res. 2002;52:69-77.

33. Terra VC, Cysneiros RM, Schwartzman JS, Teixeira MCT V, Arida RM, Cavalheiro EA, et al. Mothers of children with cerebral palsy with or without epilepsy: a quality of life perspective. Disabil Rehabil. 2011 Jan 1;33(5):384-8.

Open Access This article is licensed under a Creative Commons Attribution 4.0 International License, which permits use, sharing, adaptation, distribution and reproduction in any medium or format, as long as you give appropriate credit to the original author(s) and the source, provide a link to the Creative Commons license, and indicate if changes were made. The images or other third party material in this article are included in the article's Creative Commons license, unless indicated otherwise in a credit line to the material. If material is not included in the article's Creative Commons license and your intended use is not permitted by statutory regulation or exceeds the permitted use, you will need to obtain permission directly from the copyright holder. To view a copy of this license, visit http://creativecommons.org/licenses/ by/4.0/. 